\title{
Produção de leite por dia de intervalo de partos em um rebanho mestiço Holandês x Gir em Itaguaí, RJ
}

\section{Milk yield per day of calving interval of a holstein $\mathbf{x}$ gir crossbred catlle from Itaguaí, $\mathbf{R J}$}

\author{
Tarcísio de Moraes Gonçalves, ${ }^{\star *}$ Andréa Maria de Araújo Gabriel,, ${ }^{\star \star \star}$ Flamarion Tenório de Albuquerque, ${ }^{\star \star \star \star}$ \\ Agostinho Jorge dos Reis Camargo, ${ }^{\star \star \star \star}$ Silvino Adonias Araújo, ${ }^{\star \star \star}$ Osvaldo Almeida Resende ${ }^{\star \star \star}$
}

\begin{abstract}
Resumo
Analisou-se a performance produtiva de vacas mestiças das raças Holandesa $(H)$ e Gir $(G)$ de um rebanho localizado em Itaguaí, Rio de Janeiro (latitude $22^{\circ} 45^{\prime} \mathrm{S}$ e longitude $43^{\circ} 41^{\prime} \mathrm{W}$ ) utilizando-se dados de 1.178 lactações, abrangendo um período de dez anos (1982 a 1991). A média estimada para produção de leite por dia de intervalo de partos (PRLIP) foi $11,90 \pm 0,08 \mathrm{~kg}$. A PRLIP foi influenciado, de forma significativa $(P<0,01)$, pelo ano de parto, ordem de parto, grupo genético e período de lactação, não sendo, contudo, influenciada $(P>0,05)$ pela estação de parto. Os grupos de animais 3/4 HG, 7/8 HG e 15/16 HG apresentaram maiores índices de PRLIP em relação ao 1/2 HG. Observou-se efeito linear do período de lactação sobre a PRLIP $(b=0,011 \mathrm{~kg} / \mathrm{dia})$
\end{abstract}

Palavras-chave: bovino de leite mestiço; fatores ambientais; grupo genético; produção; produtividade.

\begin{abstract}
This work analyses the performance of Holstein $(H)$ and Gir $(G)$ crossbred cattle from Itaguaí district, Rio de Janeiro (latitude $22^{\circ}$ $45^{\prime} S$ and longitude $43^{\circ} 41^{\prime} \mathrm{W}$ ), Brazil. Data used were records of 1,178 lactations from 1982 to 1991 . The estimate average of milk yield per day of calving interval (PRLIP) was $11.90 \pm 0.08 \mathrm{~kg}$. The PRLIP was significantively influenced $(P<0.01)$ by year of calving, parity, genetic group and lactation length. However, it was influenced by season of calving. The animals $3 / 4 \mathrm{HG}, 7 / 8 \mathrm{HG}$ and 15/16 HG presented the highest index of PRLIP. It was observed linear effect of lactation length on PRLIP ( $b=0.011 \mathrm{~kg} / \mathrm{day})$.
\end{abstract}

Keywords: Dairy crossbred cattle; environmental factors; genetic group; production; and productivity.

\section{Introdução}

O retorno econômico proporcionado pelas vacas de um rebanho leiteiro é determinado, basicamente, pela produção de leite e eficiência reprodutiva, que de certo modo estão relacionadas. Sob o ponto de vista econômico, a produção de leite por unidade de tempo é mais importante que a produção de leite total (Guerra e Menendez, 1983). Através do índice quilograma de leite por dia de intervalo de partos, o proprietário pode calcular a contribuição da vaca de seu rebanho para a formação da renda bruta na venda do leite, uma vez que este índice fornece a quantidade de leite por dia de vida útil e, deste modo, permite estimar a produtividade anual do rebanho (Faria e Corsi, 1993). Assim, a avaliação dos fatores que provocam variações no desempenho produtivo de um rebanho é fundamental para a obtenção de informações que permita o estabelecimento de práticas adequadas para ajustes no manejo.
O presente trabalho objetiva avaliar a influência de fatores ambientais, do grupo genético e do periodo de lactação sobre a produção de leite por dia de intervalo de partos de um rebanho mestiço Holandês $x$ Gir.

\section{Material e métodos}

Os dados de registro de 380 vacas mestiças das raças Holandesa $(H)$ e Gir $(G)$ num total de 1.178 lactações em dez anos de atividade de uma propriedade localizada no município de Itaguaí, interior do Rio de Janeiro, foram analisados objetivando determinar a média de produção de leite por dia de intervalo de partos (PRLIP).

Os dados referentes à temperatura do ar $\left({ }^{\circ} \mathrm{C}\right)$, médias das temperaturas máximas e das mínimas $\left({ }^{\circ} \mathrm{C}\right)$, umidade relativa do $\operatorname{ar}(\%)$ e precipitação pluviométrica $(\mathrm{mm})$ foram fornecidos

\footnotetext{
- Parte da tese de mestrado apresentada à Universidade Federal Rural do Rio de Janeiro, Seropédica, RJ (UFRRJ), pelo segundo autor.

** Departamento de Zootecnia, Universidade Federal de Lavras (UFLA), Lavras, MG, Brasil

*** Médico Veterinário Autônomo, Av. Ministro Fernando Costa, 12, CEP 23835-390, Seropédica, RJ, Brasil.

**** Departamento de Reprodução Animal, UFLA, Lavras, MG, Brasil.

***** Pesquisador da Empresa de Pesquisa Agropecuária do Estado do Rio de Janeiro, Km 47 da antiga Rodovia Rio-São-Paulo, CEP 23851-970, Seropédica, RJ, Brasil
} 
pelo posto de observação meteorológica, da Estação Experimental de Itaguaí - Empresa de Pesquisa Agropecuária do Estado do Rio de Janeiro (PESAGRO-RIO). Na Tabela 1 são apresentadas as médias mensais e gerais dos dados climáticos correspondentes ao período de 1982 a 1991.

Foram estudados os efeitos fixos de ano de parto (1982 a 1991), de estação de parto (quatro estações), de ordem de parto (1 a 9), de grupo genético (1/2 HG ao PC) e o efeito linear do período de lactação sobre a PRLIP.

As vacas em lactação (divididas em três lotes) recebiam diariamente uma alimentação constituída de fubá, cevada, ração balanceada comercial e minerais, de acordo com a produção de leite e fase de lactação. Anteriormente, esta mistura sem - fubá era fornecida uma vez ao dia, passando para duas e depois para três vezes ao dia. $\mathrm{Na}$ época de seca, as vacas recebiam suplementação volumosa, constituída de silagem de milho (Zea mays, L.) e capim napier (Pennicetum purpureum, Schum.).

No período de implantação da propriedade, as novilhas eram criadas com o gado falhado; posteriormente, passaram a ser manejadas separadamente, e, de acordo com a qualidade da pastagem, recebiam até dois quilogramas da mesma alimentação fornecida às vacas em fim de lactação.

As vacas em gestação eram colocadas em piquete maternidade por cerca de 30 dias antes da data provável de parto. Nestes piquetes recebiam alimentação de acordo com a condição corporal.

Além deste manejo, as vacas foram mantidas em regime de pastejo rotativo com pastagens constituídas por capimcoloniāo (Panicum maximum) e capim-angola (Brachiaria mutica) e a água era fornecida em cocho coletivo fora dos piquetes, estando disponível várias vezes ao dia.

Tabela 1: Médias mensais de temperatura (TEMP), de temperaturas máxima (TMÁX) e mínima (TMÍN), de umidade relativa do ar (UR) e de precipitação pluviométrica (PP) da região de Itaguaí, durante o período de 1982 a 1991.

\begin{tabular}{|c|c|c|c|c|c|}
\hline Meșes & TEMP $\left({ }^{\circ} \mathrm{C}\right)$ & TMÁX $\left({ }^{\circ} \mathrm{C}\right)$ & $\operatorname{TMIN}\left({ }^{\circ} \mathrm{C}\right)$ & UR (\%) & $P P(m m)$ \\
\hline 1. Janeiro & 27,1 & 32,7 & 23,1 & 70,9 & 180,7 \\
\hline 2. Fevereiro & 27,7 & 33,8 & 23,7 & 69,6 & 125,1 \\
\hline 3. Março & 26,4 & 31,6 & 22,4 & 73,6 & 164,3 \\
\hline 4. Abril & 25,0 & 30,5 & 21,1 & 73,2 & 127,1 \\
\hline 5. Maio & 23,1 & 28,6 & 19,1 & 72,4 & 73,7 \\
\hline 6. Junho & 21,5 & 27,5 & 17,3 & 69,7 & 46,6 \\
\hline 7. Julho & 21,2 & 27,2 & 16,8 & 67,6 & 33,6 \\
\hline 8. Agosto & 21,7 & 27,8 & 17,3 & 64,8 & 28,4 \\
\hline 9. Setembro & 21,7 & 27,2 & 17,8 & 70,3 & 89,8 \\
\hline 10. Outubro & 23,5 & 28,7 & 19,4 & 69,5 & 77,8 \\
\hline 11. Novembro & 25,0 & 30,7 & 21,0 & 68,5 & 72,7 \\
\hline 12. Dezembro & 25,8 & 31,7 & 22,2 & 68,6 & 172,8 \\
\hline Média geral & 24,2 & 29,8 & 20,1 & 63,4 & $\cdots$ \\
\hline Valor anual & $\cdots$ & $\cdots$ & $\cdots$ & -- & $1.192,6$ \\
\hline
\end{tabular}

Fonte: PESAGRO-RIO - 1982 a 1991.
O rebanho era mantido estabulado para arraçoamento duas vezes ao dia em galpão aberto com cobertura de telha francesa no período de maior insolação. A ordenha era feita duas vezes ao dia sem bezerro ao pé, e o controle leiteiro, semanalmente.

As análises estatísticas foram realizadas no centro de processamento de dados da Universidade Federal de Lavras, utilizando-se do pacote estatístico SAS (Statistics Analysis System - Institute Inc., 1995). Para o estudo dos efeitos que influenciam a produção de leite por dia de intervalo de partos utilizou-se o seguinte modelo estatístico:

$Y_{i j k l m}=\mu+A P_{i}+E S T_{j}+O R P_{k}+G G_{l}+\beta\left(X_{i j k l m}-\bar{X}\right)+e_{i j k l m}$

em que :

$Y_{\text {ijkIm }}=$ PRLIP na lactação $m$, da fêmea pertencente ao grupo $\mu \quad=$ constante inerente a todas as observaçōes;

$\mathrm{Ap}_{\mathrm{i}}=$ efeito do ano do parto $i$, na qual iniciou a lactação, onde $i$

$\mathrm{EST}_{j}=$ efeito da estação do parto $j$, sendo $j=1$ (verāo), 2 (outono), 3 (inverno), 4 (primavera);

$\mathrm{ORP}_{\mathrm{K}}=$ ef eito da ordem do parto $k$, onde $k=1,2, \ldots, 9$;

$\mathrm{GG}_{1}=$ efeito do grupo genético $l$, onde $l=1(1 / 2), 2(3 / 4), 3$ (7/8),4 (15/16) e 5 (PC);

$\beta=$ coeficiente de regressāo linear da PRLIP, em função à duração da lactação;

$X_{i j k l m}=$ duração do periodo de lactação, em dias, na lactação $m$, da fêmea pertencente ao grupo genético $l$, ordem de parto $k$, parida na estação $j$, do ano $i$;

$\bar{X} \quad=\quad$ duração média do periodo de lactação, em dias;

$e_{i j k l m}=$ erro, associado a cada observação, sendo $e_{i j k l m} \sim$ NID $\left(0, \sigma^{2} e\right)$.

\section{Resultados e discussão}

A média estimada da produção de leite por dia de intervalo de partos (PRLIP), proveniente de 1.178 lactações, foi $11,90 \pm$ $0,08 \mathrm{~kg}$ e o coeficiente de variação, foi $23,58 \%$. Essa média foi superior às de rebanhos mestiços Holando-Zebu no Brasil, estudados por Madalena et al. (1983), Polastre et al. (1990) e Resende et al. (1993).

$\mathrm{O}$ ano do parto da vaca influenciou a produção de leite por dia de intervalo de partos de forma altamente significativa $(P<0,01)$. As médias estimadas para a PRLIP, de acordo com o ano de parição da vaca, são mostradas na Tabela 2. Os dados referentes ao período médio de lactação, produção média de leite e duração média do intervalo de partos, que também se encontram na Tabela 2, foram discutidos por Camargo (1994). A influência do ano de parto sobre a PRLIP pode ter sido devido às diferenças climáticas influenciando o conforto ambiental, bem como a quantidade e qualidade das forragens oferecidas aos animais ao longo dos anos, como também verificaram Pandey et al. (1988). Autores como Madalena et al. (1983), Queiroz et al. (1990) e Teodoro et al. (1990), trabalhando com diversas raças, também constataram efeitos significativos do ano de parto sobre a variável em questão. 
Tabela 2: Período médio de lactação (PL), produção média de leite (PRL), duração média do intervalo de partos (IP) e médias estimadas e respectivos erros-padrão da produção de leite por dia de intervalo de partos (PRLIP), segundo o ano de parto (AP)

\begin{tabular}{lccccc}
\hline AP & \multicolumn{2}{c}{$\mathrm{N}^{0}$ obs PL (dias) } & PRL (kg) & IP (dias) & PRLIP (kg/dia) \\
\hline 1982 & 3 & 260,00 & $3.010,00$ & 386,00 & $7,48 \pm 1,64^{\star}$ \\
1983 & 15 & 340,33 & $4.146,67$ & 438,60 & $9,48 \pm 0,78^{\circ}$ \\
1984 & 130 & 305,19 & $4.264,45$ & 387,68 & $11,15 \pm 0,29^{d}$ \\
1985 & 138 & 319,83 & $5.264,99$ & 415,09 & $12,57 \pm 0,28^{\mathrm{b}}$ \\
1986 & 166 & 308,17 & $4.855,49$ & 401,57 & $12,17 \pm 0,26^{\text {bod }}$ \\
1987 & 188 & 299,12 & $4.600,57$ & 404,79 & $11,62 \pm 0,24^{\text {bod }}$ \\
1988 & 184 & 295,15 & $4.537,29$ & 399,66 & $11,48 \pm 0,26^{\text {bod }}$ \\
1989 & 159 & 295,51 & $4.580,61$ & 398,23 & $11,58 \pm 0,26^{\text {bod }}$ \\
1990 & 137 & 293,63 & $4.961,71$ & 397,53 & $12,47 \pm 0,27^{\text {bc }}$ \\
1991 & 58 & 282,43 & $4.999,69$ & 392,72 & $14,07 \pm 0,40^{\mathrm{a}}$ \\
\hline
\end{tabular}

Médias seguidas pela mesma letra não diferem entre si, ao nível 0,05 de probabilidade pelo teste de Tukey.

* Número pequeno de observação, não diferiu estatisticamente das demais médias

A estação de parto não apresentou efeito significativo $(P>0,05)$ sobre a PRLIP. As médias da PRLIP no verão, outono, inverno e primavera foram $11,13 \pm 0,28 \mathrm{Kg} / \mathrm{dia}, 11,44 \pm 0,25 \mathrm{Kg} / \mathrm{dia}$, $11,70 \pm 0,28 \mathrm{~kg} / \mathrm{dia}$ e $11,35 \pm 0,35 \mathrm{Kg} / \mathrm{dia}$, respectivamente. $\mathrm{A}$ variável estação do parto reflete, além das condições climáticas, a qualidade e quantidade de alimento no pasto e, conseqüentemente, afeta a produção e reprodução do animal. As vacas do rebanho estudado recebiam suplementação volumosa na época da seca, constituida de silagem de milho (Zea mays, L.) e capim napier (Pennicetum purpureum, Schum.) e concentrado (ração comercial balanceada em quantidade de acordo com a sua produção) durante todo o ano. Possivelmente a constância no regime alimentar aliado às mudanças de manejo durante 0 ano, como instalação de ventiladores no estábulo e fornecimento de sombra nos piquetes, procurando minimizar os efeitos das condições climáticas, tenham contribuído para a não-existência de diferença da PRLIP nas diferentes estações de parto, conforme foi também verificado por Deshpande et al. (1992). Resultados semelhantes foram observados por Teodoro et al. (1990), Murdia e Tripathi (1992) e Resende et al. (1993).

A ordem de parto da vaca afetou significativamente $(P<0,01)$ a PRLIP. A maior produção verificada no quinto parto (Tabela 3) pode ser devida ao alcance da maturidade fisiológica que, conforme mencionou Singh (1992), normalmente ocorre em torno de oito a nove anos de idade.

Como no rebanho em questão, de acordo com Camargo (1994), a idade média estimada para o primeiro parto foi de 34,9 meses e a média estimada para o intervalo de partos foi de 13,8 meses, a maturidade fisiológica dos animais ocorreu em torno da quinta parição. O efeito da ordem de parto sobre o parâmetro em questão foi também verificado por Murdia e Tripathi (1992) e Yadav et al. (1992).
Tabela 3: Médias estimadas e respectivos erros-padrão da produção de leite por dia de intervalo de partos (PRLIP), segundo a ordem de parto (ORP)

\begin{tabular}{ccc}
\hline ORP & $N^{0}$ de observações & PRLIP (kg/dia) \\
\hline 1 & 273 & $9,61 \pm 0,26^{\mathrm{e}}$ \\
2 & 230 & $10,56 \pm 0,27^{\mathrm{d}}$ \\
3 & 197 & $11,35 \pm 0,28^{\mathrm{bcd}}$ \\
4 & 156 & $12,26 \pm 0,30^{\mathrm{ab}}$ \\
5 & 115 & $12,40 \pm 0,33^{\mathrm{a}}$ \\
6 & 80 & $11,75 \pm 0,37^{\mathrm{abc}}$ \\
7 & 57 & $12,00 \pm 0,42^{\mathrm{ab}}$ \\
8 & 36 & $11,45 \pm 0,52^{\mathrm{abcd}}$ \\
9 & 34 & $11,26 \pm 0,54^{\mathrm{abcd}}$ \\
\hline
\end{tabular}

Médias seguidas pelas mesmas letras não diferem entre si, ao nível de 0,05 de probabilidade pelo teste de Tukey.

A PRLIP foi significativamente $(P<0,01)$ influenciada pelo grupo genético das vacas. Observa-se que os animais $1 / 2$ Holando-Zebu (HG) e os animais puro por cruza (PC) possuíam menores médias de produção de leite por dia de intervalo de partos que os demais grupos genéticos, que não diferiram entre si (Tabela 4). Apesar dos animais terem sido submetidos às condições idênticas de manejo e alimentação, independentemente do grupo genético a que pertencem, podese admitir em parte que os animais 1/2 HG produziram menos devido à menor persistência de lactação (duração) e ao fato de que a ordenha era mecânica e sem bezerro ao pé, o que adquire importância ao considerar o fator descida de leite e o tempo gasto para tal quando comparada a animais com maior percentagem genética da raça Holandesa (O. $A$. Resende, comununicação pessoal), uma vez que as vacas

Tabela 4:- Médias estimadas e respectivos erros-padrão da produção de leite por dia de intervalo de partos (PRLIP), segundo o grupo genético (GG)

\begin{tabular}{lcc}
\hline GG & $N^{\circ}$ de observações & PRLIP (kg/dia) \\
\hline $1 / 2 \mathrm{HG}$ & 90 & $10,68 \pm 0,36^{\mathrm{b}}$ \\
$3 / 4 \mathrm{HG}$ & 413 & $11,93 \pm 0,23^{\mathrm{a}}$ \\
$7 / 8 \mathrm{HG}$ & 429 & $11,84 \pm 0,24^{\mathrm{a}}$ \\
$15 / 16 \mathrm{HG}$ & 203 & $11,74 \pm 0,29^{\mathrm{a}}$ \\
$P C$ & 43 & $10,84 \pm 0,48^{\mathrm{ab}}$ \\
\hline
\end{tabular}

Médias seguidas pela mesma letra não diferem entre si, ao nível de 0,05 de probabilidade pelo teste de Tukey. 
1/2 HG eram ordenhadas juntamente com as outras. A média de PRLIP dos animais PC foi aquém das expectativas, provavelmente ocorreu porque à medida que se eleva a proporção de genes da raça Holandesa nos animais de um rebanho eles se tornam mais exigentes em relação às condições ambientais, e podem não expressar plenamente sua aptidão leiteira por causa das condições climáticas, conforme mencionou Lopes (1995). A influência do grupo genético foi também evidenciada por Freitas et al. (1988) e Lemos et al. (1994). Entretanto, Madalena et al. (1983) não observaram efeito do grupo genético sobre a produção de leite por dia de intervalo de partos trabalhando com vacas mestiças das raças Holandesa (HPB) e Gir de grupos genéticos 3/4 HPB, 7/8 HPB e as HPB puras por origem e por cruza.

Houve diferença altamente significativa $(P<0,01)$ na $P R L I P$, de acordo com a duração do período de lactação. Esta influência pode ser explicada devido ao fato de que a produção de leite está associada à duração do período de lactação, conforme foi verificado por Camargo (1994), e persistência de produção. Em um período de lactação com duração de dez meses, segundo Barbosa et al. (1994), tem-se uma maior produção de leite por vaca durante sua vida produtiva e podese obter um intervalo médio de partos de 12 meses, o que favorece $o$ aumento da PRLIP, como demonstraram Faria e

\section{Referências bibliográficas}

BARBOSA, S. B. P., MANSO, H. C., SILVA, L. O. C. Estudo do período de lactação em vacas holandesas no estado de Pernambuco. Rev. Soc. Bras. Zoot., v. 23, n. 3, p. 465-475, 1994.

CAMARGO, A. J. R. Estudo de algumas características produtivase reprodutivas de um rebanho mestiço Holandês-Zebu no estado do Rio de Janeiro. 1994. 79 f. Tese (Mestrado) - Universidade Federal de Viçosa.

DESHPANDE, K. S., DESHPANDE, A. D., DESHPANDE, K. S. Genetic studies on production efficiency traits in Jersey cows. Indian J. Anim. Sci, v. 62, n. 2, p. 169-170, 1992.

FARIA, V.P., CORSI, M. Índice de produtividade em gado de leite. In: PEIXOTO, A. M., MOURA, J. C., FARIA, V. P. Bovinocultura leiteira. Fundamentos da exploração racional. 2. ed. Piracicaba: FEALQ, 1993. p. 1-22.

FREITAS, A. F., MILAGRES, J. C., DURÃES, M. C. Intervalo de partos e produção de leite por dia de intervalo de partos de vacas leiteiras mestiças. In: REUNIÄO ANUALDA SOCIEDADE BRASILEIRA DE ZOOTECNIA, 25., Viçosa, 1988. Anais..., Viçosa, SBZ, 1988. $229 \mathrm{p}$.

GUERRA, D., MENENDEZ, A. Influencia del periodo del servicio sobre la producción de leche parcial y total en vacas Holstein. Rev. Cub. Reprod. Anim., v. 9, n. 1, p. 47-57, 1983.

LEMOS, A. M., TEODORO, R. L., GONÇALVES, T. M. Intervalo de partos, produção de leite por intervalo de partos e número de serviço por concepção em vacas mestiças Holandês: Zebu. In: REUNIÄO ANUAL DA SOCIEDADE BRASILEIRA DE ZOOTECNIA, 31., Maringá, 1994. Anais... Maringá, SBZ, 1994. 209 p.

LOPES, M. A. Por que analisar curvas de lactações. Gado Holandês, v. 60, n. 446, p. 18-20, 1995.

MADALENA, F. E., VALENTE, J., TEODORO, R. L., MONTEIRO, J.B. N. Produção de leite e intervalo entre partos de vacas HPB e mestiças
Corsi (1993). O rebanho estudado era constituído de animais mestiços, onde podem ocorrer problemas de lactações curtas das vacas mestiças em sistema de ordenha sem bezerro ao pé, conforme mencionado por Madalena et al. (1983) e períodos de lactações curtos também reduzem a produção de leite.

O coeficiente de regressão estimado obtido foi $0,011 \mathrm{~kg} \mathrm{e}$ a equação de regressão foi $y=10,12+0,011 x$. Freitas et al. (1988) também observaram efeito linear do período de lactação sobre esta variável e obtiveram um coeficiente de regressão $(0,018)$ próximo ao encontrado.

De acordo com os resultados obtidos, permite-se concluir que PRLIP foi um parâmetro sujeito à influência do ano de parto, ordem de parto e grupo genético e um aumento da PRLIP pode ser esperado no quinto parto. Mesmo em condições pouco favoráveis de altas temperaturas e umidade ambiente elevada, foi possível obter bom desempenho produtivo e que, apesar da PRLIP aumentar de modo linear com o aumento da duração do período de lactação, deve-se avaliar a viabilidade econômica do aumento da duração do período de lactação acima de 305 dias. Sendo assim, a PRLIP é uma variável apropriada para avaliar desempenhos produtivos de rebanhos leiteiros por mostrar com maior objetividade a rentabilidade do animal dentro da propriedade.

HPB: Gir num alto nível de manejo. Pesq. Agropec. Bras., v. 18, n. 2, p. 195-200, 1983.

MURDIA, C. K., TRIPATHI, V. N. Effect of farm, period., season and parity on performance traits of Jersey cattle. Indian J. Anim. Sci, v. 62, n. 2, p. 177-180, 1992.

PANDEY, H. S., PANDEY, N. N., JANA, D. N., NAUTIYAL, L. P. First lactational production performance of three breed interse crosses. Indian Vet. J., v. 65, n. 9, p. 801-807, 1988.

POLASTRE, R., PONS, S. B., BACCARI, F.JR. Avaliação do programa de seleção e tendências ambientais de algumas características de produção e reprodução em um rebanho mestiço Holandês-Zebu. Rev.Soc. Bras. Zoot., v. 19, n. 1, p. 31-38, 1990.

QUEIROZ, S. A., ALBUQUERQUE, L. G., LOBO, R. B. Desempenho reprodutivo e produtivo de um rebanho mestiço Holandês. Parâmetros fenotípico e genotípico. In: REUNIÄO ANUALDA SOClEDADEBRASILEIRA DEZOOTECNIA, 27., Campinas, 1990. Anais..., Campinas, SBZ., 1990. $497 \mathrm{p}$.

RESENDE, O. A., ARONOVICH, S., PIRES, J. C., CARVALHO, S.R., CASTAGNA, A. A. Produtividade do sistema de produção de bovinos de leite em várzeas úmidas. In: REUNIÄO ANUALDA SOCIEDADE BRASILEIRA DE ZOOTECNIA, 30., Rio de Janeiro, 1993. Anais... Rio de Janeiro, SBZ, 1993. $566 \mathrm{p}$.

SINGH, S. K. Factors affecting some milk production efficiency traits in Sahiwal cattle. Indian J. Anim. Sci., v. 62, n. 4, p. 346-350, 1992.

TEODORO, R. L., LEMOS, A. M., FREITAS, A. F., MILAGRES, J. C. Comparação do desempenho de cruzamento HPB x Gir com o de Jersey ou Schwyz x (HPB $\times$ GIR). 3- Intervalo de partos e produção de leite, gordura e proteína por intervalo de partos. In: REUNIÃO ANUAL DA SOCIEDADEBRASILEIRA DE ZOOTECNIA, 27. Campinas, 1990. Anais..., Campinas, SBZ, 1990. 510 p.

YADAV, A. S., RATHI, S. S., DAHIYA, S. P., ARORA, D. N. Factors affecting some performance traits in Sahiwal cattle. Indian J. Dairy Sci., v. 45, n. 10, p. 522-527, 1992. 